\title{
UX Design na Criação e Desenvolvimento de Aplicativos Digitais
}

\section{$X$ Design in Creation and Digital Applications Development}

\section{Resumo:}

Concebido em 1990, pelo psicólogo cognitivo Donald Norman, o termo User Experience (UX) tem como objetivo abranger todos os elementos que envolvem a experiência do usuário com um produto ou uma empresa, conforme afirma Norman (apud BULEY, 2013). Já sua área de atuação, denominada User Experience Design (UX Design), segundo Unger e Chandler (2010), estuda como a criação e sincronização desses elementos pode afetar a experiência do usuário de modo a influenciar suas percepções e comportamento. Tendo em vista a grande concorrência, o alto grau de exigência dos usuários na busca pela extrema qualidade e satisfação que os produtos devem Ihe proporcionar, bem como a complexidade do processo e metodologias que envolvem as etapas do UX, A finalidade desse artigo é discutir e demonstrar as possíveis possibilidades que envolvem a criação, a construção e o desenvolvimento do UX Design em toda a extensão de um projeto através da descrição de três metodologias que possuem em comum a aplicação do design centrado no usuário. Para tal, foi realizada uma revisão bibliográfica visando discutir e compreender as etapas dos processos que envolvem as questões projetuais na criação e desenvolvimento de aplicativos digitais e a complexidade que estas etapas e metodologias buscam solucionar nas amplas e ainda recentes discussões que abrangem o UX Design, fazendo o uso de autores conceituados na área de UX como Garrett (2011), Unger e Chandler (2010) e também na área de usabilidade, como Morville (2004) e Nielsen; Loranger (2007).

Palavras-chave: User experience. Aplicativos digitais. Design.

Abstract:

Designed in 1990 by cognitive psychologist Donald Norman, the term User Experience (UX) aims to cover all elements that involve the user experience with a product or a company, as stated Norman (cited Buley, 2013). Since its area of operation, called User Experience Design (UX Design), according to Unger and Chandler (2010), studies how the creation and synchronization of these elements can affect the user experience in order to influence their perceptions and behavior. Given the fierce competition, the high level of demand from users in the quest for extreme quality and satisfaction that products must provide you and the complexity of the process and methodologies involving the stages of the UX, the purpose of this article is to discuss and demonstrate the potential possibilities that involve the creation, construction and development of UX Design throughout the length of a project by describing three methodologies that have in common the application of user centered design. To this end, a literature review was conducted to discuss and understand the process steps involving projective questions in the creation and development of digital applications and the complexity of these steps and methodologies seek to address the large and still recent discussions covering the UX Design, making the use of respected authors in the UX area as Garrett (2011), Unger and Chandler (2010) and also in the field of usability, as Morville (2004) and Nielsen (2007).

Keywords: User experience. Digital applications. Design

SOUSA, Milene Rocha de; BERTOMEU, João Vicente Cegato. UX Design na Criação e Desenvolvimento de Aplicativos Digitais. Informática na Educação: teoria e prática, Porto Alegre, v. 18, n. 2, p. 127143, jul./dez. 2015.

\section{Milene Rocha de Sousa}

\section{João Vicente Cegato Bertomeu}

\section{Introdução}

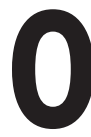
riginado em 1990, pelo psicólogo cognitivo Donald Norman, o termo User Experience, popularmente conhecido como UX, foi concebido com o intuito de abranger todos os aspectos que envolvem a experiência do usuário com um produto que, segundo Norman (apud BULEY, 2013), consistia numa área muito extensa para ser sintetizada apenas como interface humana e usabilidade.

Já sua área de atuação, denominada UX Design, é definida por Unger e Chandler (2010) como a criação e sincronização de elementos que afetam a experiência do usuário de modo a influenciar suas percepções e comportamento.

Atualmente, em virtude da grande oferta de produtos, o termo UX e sua recente área 
de atuação vêm ganhando grande notoriedade como parte fundamental do projeto de concepção de um produto, visto que num mercado tão concorrido, as empresas necessitam atender cada vez mais as exigências em relação à extrema qualidade e satisfação que os produtos devem proporcionar aos seus compradores nas diversas etapas de experiência de consumo.

Segundo Lowdermilk (2013), os usuários esperam ter uma experiência marcante com os produtos dos quais interagem, já que grande parte deles os ajuda a alcançar seus objetivos, ao passo que são poucos os que tornam essa tarefa envolvente e prazerosa.

Sendo assim, esse estudo tem como objetivo discutir os processos projetuais do $U X$ Design, assim como procurar compreender as possibilidades metodológicas mais utilizadas, demonstrando a importância da aplicabilidade do UX Design no processo de concepção de aplicativos digitais em sua totalidade, apontando o detalhamento das etapas mais relevantes a partir do apontamento e análise de três metodologias que se complementam e são utilizados no design pela ótica das definições de $U X$. Dentre as principais metodologias, temos o modelo de Garrett (2011) que propõe um desmembramento do projeto em cinco planos - estratégia, escopo, estrutura, esqueleto e superfície - para facilitar a compreensão e o desenvolvimento de projetar a experiência do usuário.

$\mathrm{Na}$ metodologia de Unger e Chandler (2010), todos os projetos que possuem como foco o usuário, dividem-se essencialmente em: planejar a estratégia de abordagem e estrutura geral da equipe; definir os requisitos do projeto; fazer uso do design de interação e princípios de design visual como ferramentas para tornar os requisitos reais; desenvolver, testar e refinar a solução; implantar o resulta- do por meio de treinamento e um lançamento planejado; estender o projeto para melhorias baseado nos feedbacks.

Já o modelo de Lowdermilk (2013), sugere uma divisão contendo os seguintes elementos fundamentais: declaração de missão da equipe, detalhes do projeto, requisitos de usuário, requisitos funcionais, diagramas de fluxo de dados e protótipos.

Todas as metodologias possuem em comum a aplicação do chamado design centrado no usuário que, segundo Garrett (2011), consiste na prática de se atentar às necessidades e desejos dos usuários em todas as etapas do desenvolvimento de um produto. Seu objetivo é entender todas as possibilidades ao qual o usuário está suscetível na interação com o produto e compreender suas expectativas durante esse processo.

Para isso, foi realizada uma revisão bibliográfica valendo-se dos principais autores conceituados na área de UX como Garrett (2011), Unger e Chandler (2010) e Lowdermilk (2013) que possuem metodologias de projeto que contemplam todas as etapas de construção de um produto descrevendo desde a idealização da estratégia até a fase de prototipação do produto. Foram utilizados também autores considerados precursores na área de usabilidade, como Morville (2004) e Nielsen (2007), que tiveram uma grande contribuição para o avanço dos estudos que originaram o que hoje é conhecido como User Experience.

Por fim, constatou-se não somente o sólido embasamento do User Experience que, embora ainda não apresente uma padronização nas disciplinas que o constituem, tem sua origem, segundo Buley (2013), em estudos iniciados há mais de um século, como também comprovaram sua forte ligação e responsabilidade com o sucesso de um projeto, visto que 
não há maiores conhecedores sobre um produto do que seus próprios usuários, segundo Saffer (2007).

\section{Metodologia e Métodos}

Para demonstrar a importância do UX Design em todo o processo de concepção de um produto, foi realizada uma pesquisa qualitativa por meio da descrição de três metodologias que contemplam todas as etapas de construção de um aplicativo digital, abrangendo desde a idealização da estratégia até a fase de prototipação do produto.

O artigo foi então dividido em quatro partes, sendo a primeira parte uma contextualização do tema. Num primeiro momento foram reunidas as principais definições de User Experience Design sob o ponto de vista de diferentes autores, entre os quais estão Nielsen, principal idealista mundial em usabilidade na Web, Norman (apud BULEY, 2013), psicólogo cognitivo e idealizador do termo UX, e Saffer (2007), amplamente reconhecido por seus projetos na área de Design de Interação. Para concluir essa primeira fase, foi incluído um breve histórico sobre o surgimento do termo User Experience utilizando-se de informações relatadas por Buley (2013).

$\mathrm{Na}$ segunda parte do artigo foi realizada uma discussão sobre usabilidade e experiência que buscou demonstrar, por meio de algumas constatações de autores distintos, as consequências de produtos que são projetados apenas pelo viés da usabilidade. Consequências essas que podem acarretam desde a perda de lucro de uma empresa, uma experiência ruim para o usuário ou até, em casos mais extremos, acidentes fatais.

Também foram ressaltadas sete características pautadas nos estudos de Morville (2004), um dos pioneiros nos campos de arquitetura de navegação e experiência do usuário, no qual reafirmou a importância do projeto não ser apenas usual. Segundo o autor, para se chegar o mais próximo de uma experiência significativa e prazerosa para o usuário, o projeto deve ser útil, usual, desejável, encontrável, acessível, ter credibilidade e ser valioso.

$\mathrm{Na}$ terceira parte, foram apresentadas as três metodologias utilizadas nesse estudo, a metodologia de Garrett (2011), de Unger e Chandler (2010) e de Lowdermilk (2013), elencando as etapas que constituem cada um dos modelos.

E por fim, a descrição da aplicabilidade do UX Design na concepção de um novo produto em sua totalidade, detalhando todas as etapas das três metodologias que se complementam entre si e possuem como ponto crucial o uso do design centrado no usuário que, segundo Garrett (2011), consiste na prática de se atentar às necessidades e desejos dos usuários em todas as etapas do desenvolvimento de um produto.

\section{0 que é User Experience Design?}

Unger e Chandler (2010) definem User EXperience Design, também conhecido como UX Design, como a criação e sincronização de elementos que afetam a experiência do usuário com uma empresa particular de modo a influenciar suas percepções e comportamento. Elementos esses que podem incluir o tato (produtos tangíveis e suas embalagens), a audição (comerciais de TV ou rádio), o olfato (aroma de pão fresco em uma padaria) e também produtos dos quais os usuários interagem no plano virtual, como interfaces digitais (sites e aplicativos mobile). 
Garrett (2011) acrescenta que o User Experience está relacionado ao funcionamento externo de um produto, momento em que ocorre a interação com o usuário, e não ao funcionamento interno do mesmo. Segundo o autor, a expressão a forma segue a função, originária do design de produto, faz sentido somente quando se refere ao funcionamento interno do produto, partes das quais o usuário não tem acesso. Quando se trata da parte externa, no qual o utilizador interage, a forma correta não é ditada pela funcionalidade e sim pela psicologia e comportamento dos usuários.

De acordo com Nielsen e Norman (2014), o UX Design vai muito além de entregar produtos que os usuários querem ou mesmo fornecer recursos inclusos em sua lista de anseios. Para alcançar uma experiência de qualidade, é necessário que haja uma fusão perfeita de diversas disciplinas como mostra o diagrama de Saffer (2007):

Figura 1 - Diversas Disciplinas do User Experience Design.

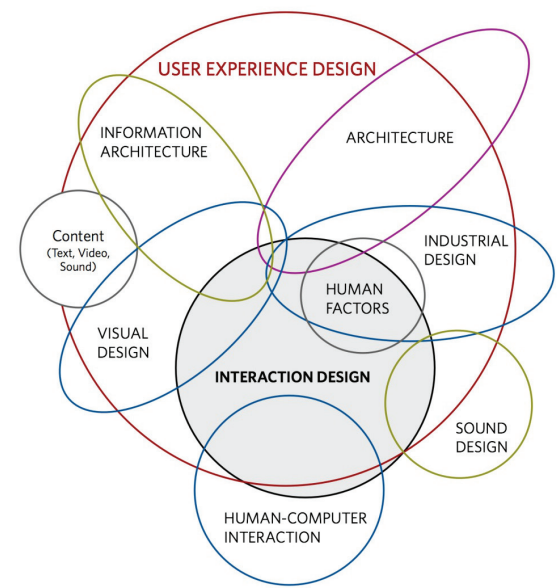

Fonte: Saffer, 2007, p. 20.

Saffer (2007) afirma que todas as disciplinas, ou pelo menos grande parte delas, estão sob o prisma do User Experience Design, no qual o UX Design é o parâmetro para que as demais estejam em harmonia no instante em que o usuário interage com o produto ou serviço.

Norman (apud BULEY, 2013), fundador do termo User Experience, afirma que decidiu criá-lo para abranger todas as disciplinas que proporcionam a experiência do usuário que, até então, eram descritas apenas como pesquisa sobre interface humana. Segundo ele, o UX consistia numa área muito extensa para ser resumida apenas como interface humana e usabilidade.

Buley (2013) ressalva que o fato do UX Design ser um campo recente, não há uma padronização nos títulos das disciplinas que o constituem gerando assim dúvidas quanto ao nome das profissões. Tanto Buley (2013), como Saffer (2007) e Garrett (2011) afirmam que existe uma grande possibilidade de encontrar diversos termos semelhantes para designar a mesma função, como por exemplo, design de informação para se referir a mesma ocupação que muitos conhecem como arquiteto da informação.

Abaixo, uma sucinta descrição de alguns dos cargos mais conhecidos que em conjunto integram o UX Design.

A arquitetura de informação (AI) é o campo responsável pelo esqueleto do site sobre o qual as demais disciplinas são construídas. Segundo Morville (2002), a arquitetura de informação é a junção da organização, rotulagem e esquemas de navegação em um sistema de informação para tornar o acesso dos usuários ao conteúdo fácil e intuitivo.

O design de interação, de acordo com Saffer (2007), é um campo multidisciplinar que tem suas origens no desenho industrial, fatores humanos e interação humano-computador. Sua função é facilitar as interações entre os seres 
humanos, promovendo a comunicação entre duas ou mais pessoas e também entre pessoas e máquinas que possuam inteligência artificial capaz de responder ao usuário de alguma forma, como o computador ou telefone celular, por exemplo.

O design de comunicação, mais conhecido como design visual, tem como meta a elaboração da linguagem visual adequada para a comunicação do conteúdo e objetivos do produto. Consiste na disciplina responsável por toda a concepção visual do site ou aplicativo que compreende a paleta de cores, tipografia, entre outros elementos que compõem o layout.

O desenho industrial, por sua vez, é o campo responsável pela criação, desenvolvimento e execução de produtos que agrega estética e funcionalidade, estudando a função dos objetos e sua aplicação na prática.

Os fatores humanos investigam se o produto é compatível com as necessidades, habilidades e limitações humanas, tanto físicas como psicológicas.

Já a interação humano-computador (HCI) está diretamente ligada ao design de interação, entretanto seus métodos são quantitativos e seu foco é na relação entre os seres humanos e os computadores, ao passo que o design de interação, estuda como os humanos se relacionam entre si.

Apesar da recente notoriedade que a área de User Experience vem ganhando em virtude da necessidade das empresas em atingir um alto grau de eficiência e aceitabilidade dos projetos por parte de seus consumidores, de acordo com Buley (2013), o campo de UX possui suas origens em estudos iniciados há mais de um século. Segundo o autor, para melhor compreensão de onde tudo começou, é preciso voltar ao início do século XX, momento em que as empresas cresceram, a mão de obra qualifi- cada estava se tornando escassa e os avanços na tecnologia influenciavam a indústria a alavancar os limites do trabalho humano.

Foi nessa época que Frederick Winslow Taylor e Henry Ford, mesmo sendo criticados pela forma desumana como tratavam os trabaIhadores, foram considerados os pioneiros no método como conduziam o trabalho humano de forma a torná-lo mais eficiente e produtivo. A pesquisa de Taylor sobre a eficiência das interações entre os trabalhadores e suas ferramentas foi precursora para os pensamentos que hoje constituem os profissionais de User Experience (BULEY, 2013).

Anos mais tarde, na primeira metade do século $X X$, um corpo emergente de pesquisadores desenvolveu o que futuramente seria os campos de fatores humanos e ergonomia, e posteriormente, ciência cognitiva. O objetivo dos cientistas era descobrir o potencial do computador como ferramenta para aumentar as capacidades mentais dos seres humanos.

Os grandes avanços dos anos seguintes nas pesquisas sobre computadores para uso humano foram de autoria do PARC, um centro de pesquisas da Xerox fundado em meados de 1970, que, motivados pela exploração de inovações tecnológicas no ambiente de trabalho, elaboraram muitas convenções de interface que ainda hoje são utilizadas, como a interface gráfica, o mouse e os gráficos bitmaps.

Os projetos do PARC também tiveram grande influência sobre a comercialização da primeira interface gráfica disponível para o usuário, intitulado Apple Macintosh.

Entretanto, mesmo com os avanços relevantes nas pesquisas de interação humano-computador, o termo User Experience foi originado somente em 1990 pelo psicólogo cognitivo Donald Norman quando este se juntou a equipe da Apple. 
Segundo Buley (2013), Norman criou o termo para abranger o que até então era descrito como pesquisa sobre interface humana. De acordo com Norman (apud BULEY, 2013), o termo foi inventado com o objetivo de abranger todos os aspectos da experiência de uma pessoa com um sistema que inclui o design industrial, gráfico, a interface, a interação física e a interação manual. Norman (apud BULEY, 2013), defende que os campos de interface humana e usabilidade eram muito restritos para englobar uma área tão extensa.

Com o aumento da computação pessoal na década de 80 e, posteriormente, a popularização da internet na década de 90, as interfaces gráficas, a ciência cognitiva e os projetos pensados nos usuários tornaram-se base para o estudo da HCI. Como resultado, os computadores ficaram mais acessíveis a uma grande massa da população e, consequentemente, surgiu a necessidade de compreender e otimizar o seu uso.

Logo, o HCI popularizou os conceitos de usabilidade e design de interação e, juntamente com o estouro da internet, mais pessoas se tornaram experientes e novos empregos com títulos como web designer e arquiteto da informação surgiram fazendo com que o campo de User Experience tivesse um rápido crescimento.

\section{Usabilidade X Experiência}

Lowdermilk (2013) afirma que os usuários esperam ter uma experiência marcante com os produtos dos quais interagem, visto que a grande maioria deles os auxiliam no cumprimento de seus objetivos, enquanto são poucos os que tornam essa tarefa envolvente e prazerosa.
Segundo Garrett (2011), na web ou em qualquer aplicativo interativo, o UX Design torna-se ainda mais relevante por se tratar de um produto de auto-entendimento. Não existe manual de instruções, treinamento ou representantes que auxiliem os usuários a se orientarem pelo site ou aplicativo digital. Somente sua inteligência e experiência pessoal poderão guiá-los no cumprimento de suas tarefas.

Outro ponto significativo em relação a produtos tecnológicos é o sentimento de frustração causado por aplicativos complexos. De acordo com Garrett (2011), os usuários possuem o hábito de se culpar quando não conseguem atingir seus objetivos, sendo mais fácil julgarem que estão fazendo algo errado do que encontrar falhas no sistema.

Vale ressaltar que apesar do foco no aspecto digital, conforme colocação de Unger e Chandler (2010), é de extrema importância estar atento aos demais pontos de contato entre o consumidor e a empresa, visto que a experiência do usuário com o produto pode ser afetada de diversas maneiras. Nem o melhor design tem o poder de compensar uma reputação negativa resultante de um atendimento ruim ou fornecer a satisfação que um produto de má qualidade não foi capaz de promover.

Morville (2004), em concordância com os demais autores, também defende que o produto deve ser pensado além da usabilidade, que, apesar de primordial, é apenas um dos aspectos que abrangem a experiência de uso. Para exemplificar, o autor divide em sete as facetas de experiência do usuário, destacando as principais características que o projeto deve alcançar para resultar em uma experiência significativa e valiosa, conforme ilustrado no diagrama abaixo: 
Figura 2 - Facetas da Experiência do Usuário.

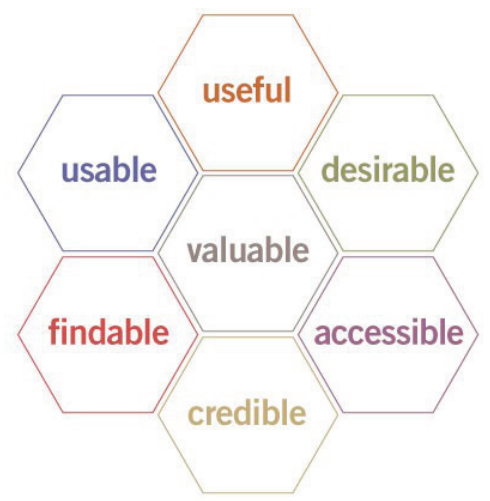

Fonte: Morville, 2004, p.42.

A primeira característica é ser útil. Morville (2004) afirma que o aplicativo ou site não deve ser útil apenas para a empresa ou gestor do projeto, mas deve ser útil principalmente para o público consumidor. De acordo com o autor, os profissionais envolvidos na concepção de um projeto devem traçar soluções baseadas não somente nos requisitos propostos pelos gestores, mas também usar o conhecimento e a criatividade para extrair dos usuários soluções criativas e inovadoras em conformidade com os objetivos do projeto.

A segunda característica elencada por Morville (2004) é ser usual. A facilidade de uso é um aspecto vital num produto embora um projeto focado apenas na interação humano-computador jamais contemplará todas as necessidades dos usuários, conforme afirma Morville (2004). A usabilidade está ligada apenas a aspectos funcionais, como a rapidez com que os usuários conseguem utilizar um produto, sua eficiência e o quanto estão propensos a erros, ao passo que a experiência também envolve aspectos cognitivos e emocionais.

Ser desejável é o terceiro aspecto descrito por Morville (2004). Para ele, a busca pela usabilidade deve estar atrelada ao desejo pela marca ou produto. Além dos aspectos concretos de um projeto, é preciso atentar-se aos aspectos subjetivos, como o relacionamento emocional estabelecido entre o usuário e o produto e também entre o usuário e a organização.

Outra característica importante, de acordo com Morville (2004), é ser encontrável. O site ou aplicativo deve auxiliar o usuário a encontrar aquilo que procura, dando todo o apoio necessário para que consigam atingir seus propósitos.

Ser acessível é outro aspecto indispensável. Da mesma forma que no mundo físico, no qual os estabelecimentos comerciais possuem elevadores e rampas de acesso para pessoas com deficiência, os sites também devem possuir mecanismos que os tornem acessíveis. Segundo o autor, pessoas com algum tipo de deficiência correspondem a $10 \%$ da população.

Outros dois aspectos fundamentais para Morville (2004) é ter credibilidade e ser valioso. Credibilidade porque o usuário raramente irá entrar e usufruir de um produto que não Ihe passa confiança e credibilidade. E valioso, pois o site deve ter valor tanto para os usuários como para os stakeholders, uma vez que da mesma forma que o produto deve satisfazer seus consumidores, também deve atingir as metas de lucro estipuladas pela empresa. No caso de empresas sem fins lucrativos, ressalva Morville (2004), a experiência do usuário deve realçar a missão da organização.

Para Garrett (2011) e Norman (2014) a falta de UX Design no desenvolvimento de projetos pode acarretar em consequências ainda mais sérias do que a perda de lucro para uma empresa ou uma experiência desagradável para o usuário.

Em seu livro, Garrett (2011) cita algumas situações cotidianas que podem ser afetadas pela falta de UX em produtos ou serviços 
como, por exemplo, enfrentar uma fila enorme em um posto de gasolina ao tentar abastecer 0 carro antes de ir para o trabalho. Nesse caso, afirma o autor, essa situação de stress poderia ser evitada se o sistema tivesse sido projetado pensando no usuário. Dessa forma, a atendente não teria dificuldade em operar um sistema complexo causando uma lentidão no atendimento e o cliente, por sua vez, não se atrasaria para chegar ao trabalho.

Já Norman (2014) defende a importância de projetos que tenham como principal foco o usuário devido aos inúmeros acidentes fatais ocasionados por erro humano. Segundo o autor, mais de $90 \%$ dos acidentes de trabalho são atribuídos a erro humano, sendo a grande maioria deles, causados por um desenho inadequado de equipamentos ou procedimentos.

Seja por motivos graves, como reduzir o número de acidentes fatais ocasionados por projetos mal desenhados, conforme alertado por Norman (2014), ou de menos impacto, como a necessidade de produtos que satisfaçam seus compradores, citado por Lowdermilk (2013) ou Garrett (2011), o fato é que o caminho para a inovação e sobrevivência de uma organização não está em recursos tecnológicos ou em sistemas extremamente funcionais, mas na junção desses aspectos alinhados aos desejos e necessidades dos usuários.

\section{UX Design no Processo de Desen- volvimento de Aplicativos Digitais}

Tendo em vista a importância de conceber produtos que estejam alinhados as necessidades e expectativas dos usuários conforme citado no tópico anterior, para chegar o mais próximo de experiências relevantes, eficientes e prazerosas para os consumidores é preciso fazer uso do chamado design centrado no usuário. Garrett (2011) define como a prática de se atentar às necessidades e desejos dos usuários em todas as etapas de desenvolvimento de um produto com o intuito de entender as possibilidades, as quais ele está suscetível e compreender suas expectativas durante esse processo de interação.

Saffer (2007) reforça a importância da participação dos usuários em todas as etapas de um projeto, pelo simples fato de não existir melhores conhecedores sobre um produto do que seus próprios consumidores e cabe aos designers, a missão de descobrir quais são suas necessidades, preferências e objetivos.

E para alcançar essa meta, Unger e Chandler (2010) afirmam que todos os projetos centrados no usuário dividem-se basicamente em seis etapas: planejar a estratégia de abordagem e estrutura geral da equipe; definir os requisitos do projeto; fazer uso do design de interação e princípios de design visual como ferramentas para tornar os requisitos reais; desenvolver, testar e refinar a solução; implantar o resultado por meio de treinamento e um lançamento planejado; estender o projeto para melhorias baseado nos feedbacks.

Já o modelo de Lowdermilk (2013) sugere uma divisão contendo os seguintes componentes principais: declaração de missão da equipe, detalhes do projeto, requisitos de usuário, requisitos funcionais, diagramas de fluxo de dados e protótipos.

Na visão de Garrett (2011), para facilitar o desenvolvimento e a compreensão de projetar a experiência do usuário é preciso desmembrar o projeto em cinco planos: estratégia, escopo, estrutura, esqueleto e superfície. Os cinco planos devem ser construídos de baixo para cima, no qual as decisões a serem tomadas ao longo das etapas passam do nível abstrato para 
o concreto, conforme demonstrado na figura a seguir:

Figura 3 - Elementos da Experiência do Usuário.

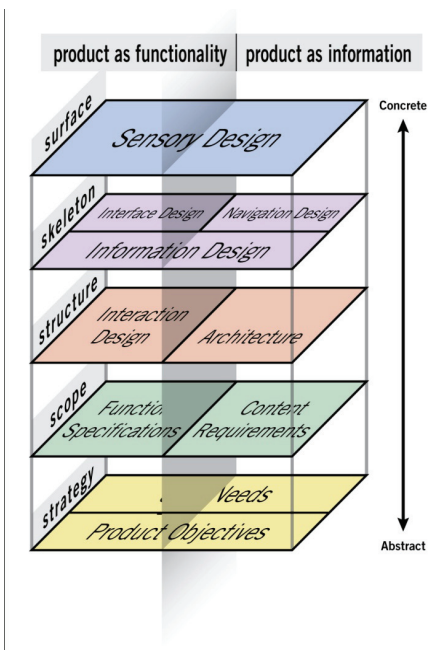

Fonte: Garrett, 2011, p. 29.

\subsection{Conceituações de Fases do Projeto: da estratégia ao escopo}

Unger e Chandler (2010) defendem que, apesar de cada projeto de site ou aplicativo possuir desafios específicos de características e funcionalidades, todos dispõem de um contexto mais abrangente que deve ser compreendido e integrado ao planejamento. Esse contexto, denominado pelos autores como ecossistema do projeto, consiste no conhecimento do ambiente organizacional (a cultura da empresa), do tipo de projeto que será desenvolvido e das pessoas que farão parte da equipe (incluindo suas funções e responsabilidades). Entender esse ecossistema, para Unger e Chandler (2010), significa adquirir um conhecimento valioso para as etapas do projeto e também para as relações interpessoais com a equipe.
No modelo de Lowdermilk (2013), algo relevante a ser considerado é a elaboração de uma declaração de missão da equipe. O objetivo, segundo o autor, é a definição de uma meta a ser alcançada e validada ao final do projeto.

Já na visão de Garrett (2011), a primeira etapa para iniciar um projeto centrado no usuário é o chamado plano da estratégia. Nesse plano são definidos os objetivos do produto e as necessidades dos usuários que servirão de base para os planos seguintes.

Ainda segundo o autor, a causa mais frequente para o fracasso de um site não é a tecnologia e nem a experiência do usuário, mas a falta de resposta para duas perguntas básicas: quais são os objetivos que a organização quer atingir com o produto e quais os objetivos impostos pelos usuários do produto.

Em concordância, Lowdermilk (2013) também defende a importância de um plano estratégico antes de iniciar o projeto centrado no usuário para não correr o risco de perder tempo e dinheiro projetando algo desnecessário. Para o autor, possuir um plano estratégico é uma forma de garantir o sucesso, uma vez que não somente ajuda a compreender melhor as necessidades dos usuários, como também se torna um ponto de partida para o feedback imediato.

$\mathrm{Na}$ etapa seguinte do modelo de LowdermiIk (2013), intitulada como detalhes do projeto, ele recomenda a inclusão do título e uma descrição do projeto, uma lista de stakeholders e uma avaliação de impacto.

O título e a descrição devem refletir o escopo do projeto, porém a descrição, além do escopo do projeto, também deve resumir o objetivo do mesmo. Na lista de stakeholders deve conter uma descrição do público-alvo, caso este seja direcionado para um grupo específico de pessoas. 
Em relação à definição do objetivo do projeto, Unger e Chandler (2010) acrescentam que o objetivo precisa estar em concordância com as iniciativas estratégicas da empresa. Ainda segundo os autores, um objetivo sólido possui três características importantes: fácil compreensão, evita termos técnicos; concreto, não possui afirmações vagas; e mensurável, faz uso de definições concretas que permitem a medição como forma determinante do sucesso. Como exemplo, Unger e Chandler (2010), sugerem que ao invés de possuir o objetivo de aumentar o tráfego de um site, o ideal seria torná-lo tangível como aumentar a receita de vendas online em dez por cento.

Definido o objetivo do produto, a coleta de requisitos dos usuários é a fase mais significativa de todo o processo. Para compreender as necessidades dos usuários ou testar seu comportamento, no caso do redesenvolvimento de um design, existem várias técnicas de pesquisas que podem ser aplicadas ao longo do desenvolvimento do projeto. Entretanto, Unger e Chandler (2010) descrevem passos básicos sobre como essa pesquisa deve funcionar.

Primeiro são definidos grupos de usuários primários, nos quais são descritos os principais perfis de públicos que serão recrutados para a pesquisa. Em seguida, é realizada a pesquisa fazendo o uso de uma ou mais técnicas compatíveis com os objetivos do projeto. Aplicada à pesquisa, os resultados devem ser validados para que, a partir das informações coletadas, seja possível a descrição detalhada de perfis de usuários padrões por meio da criação de personas.

Garrett (2011), Lowdermilk (2013) e Unger e Chandler (2010) defendem a criação de personas, uma vez que a coleta de muitos dados ao longo das pesquisas pode resultar na perda de foco dos usuários reais do produto devido ao grande volume de informações.

Personas são documentos que descrevem personagens fictícios, construídos a partir da síntese de comportamentos observados dentre a gama de usuários reais. De acordo com Vianna et al. (2012, p. 80): "Representam as motivações, desejos, expectativas e necessidades, reunindo características significativas de um grupo mais abrangente". As personas também servem como constantes lembretes dos usuários, sendo muito utilizadas para validação de ideias e resolução de conflitos na tomada de decisões importantes durante o processo de design.

Finalizada a etapa de estratégia do projeto, de acordo com Garrett (2011), o próximo plano é chamado plano de escopo. Nele, as necessidades dos usuários e os objetivos do produto devem ser transformados em requisitos específicos para o conteúdo e funcionalidades que o mesmo irá oferecer.

Segundo o autor, definir o escopo de um projeto é determinar um processo de extrema importância que resultará em um produto assertivo, uma vez que é possível presumir eventuais conflitos e problemas graves ainda na fase de conceituação. De posse desse documento é possível precisar quais problemas deverão ser corrigidos de imediato e os que poderão ser resolvidos posteriormente.

Requisitos funcionais, alerta Lowdermilk (2013), não devem ser confundidos com requisitos dos usuários. Enquanto os requisitos dos usuários referem-se ao que eles necessitam, os requisitos funcionais indicam o que a aplicação precisa ter para atender as solicitações dos usuários.

Tanto Garrett (2011) como Unger e Chandler (2010) apontam duas importantes razões para se definir o escopo de um projeto. A primeira delas é evitar a inclusão de ideias que 
não são condizentes com os objetivos estratégicos. Ambos os autores afirmam que nessa fase do projeto existe uma grande propensão de surgir diversas ideias - que podem ser sugestões ou críticas - de várias pessoas com pontos de vista distintos, tanto de dentro da organização quanto dos usuários. E para tornar essas ideias úteis para o projeto, é preciso validá-las antes de transformá-las em requisitos ou descartá-las. São os requisitos, acrescenta Unger e Chandler (2010) os responsáveis por fornecer insights para o produto, representar e consolidar as necessidades dos stakeholders, dar direção para o projeto e servir como constante material de apoio e consulta.

A segunda razão importante, destacada por Unger e Chandler (2010) em concordância com Garrett (2011), é deixar evidente para todos os envolvidos quais são os objetivos para que todos estejam cientes quando eles forem alcançados. Isso pode evitar futuros problemas como o redesenho do projeto, perda de tempo e dinheiro e uma distinção entre o escopo e a experiência final do usuário.

Caso o aplicativo ou site dependa de um banco de dados ou de vários, Lowdermilk (2013) acrescenta a importância de incluir um diagrama de fluxo de dados de modo que a equipe tenha uma visão geral de como os dados são estruturados, a forma como se conectam e como é possível acessá-los. Outra ferramenta útil, segundo o autor, é o diagrama de fluxo de trabalho que pode ser inserido em projetos que possuam uma série de etapas complexas para a realização de uma funcionalidade ou o envolvimento de várias pessoas para alcançar um resultado estipulado.

\subsection{Conceituações do Desenvolvimento do Projeto: da estrutura à finalização}

Estabelecido os requisitos para o desenvolvimento do produto, a etapa seguinte consiste em colocar em prática a forma como esses requisitos irão se encaixar resultando num produto final coerente. O próximo plano, de acordo com Garrett (2011), é o desenvolvimento de uma estrutura conceitual, denominado plano da estrutura, no qual são utilizados a arquitetura de informação e o design de interação. Nesse plano, as questões abstratas da estratégia e do escopo começam a se tornar fatores concretos para a experiência do usuário.

A arquitetura da informação, de acordo com Unger e Chandler (2010), é responsável pela criação de modelos de informação por meio da organização, agrupamento e ordenação do conteúdo fornecendo suporte para a navegação ser facilmente utilizada e compreendida.

Já o design de interação, segundo Garrett (2011), se preocupa em definir a forma como o sistema irá responder às ações do usuário. O autor compara essa interação a uma dança, na qual o usuário se move ao redor do sistema e este responde ao usuário que, por sua vez, volta a se mover em resposta ao sistema dando sequência a uma dança contínua.

No plano seguinte, denominado plano do esqueleto, conforme elencado por Garrett (2011), trata-se do aperfeiçoamento da estrutura criada no plano anterior focando em aspectos específicos da interface por meio do design de interface, design de navegação e design de informação.

Nessa etapa, Garrett (2011) destaca a importância da utilização de convenções e metáforas, uma vez que o hábito e o reflexo são a base para grande parte da interação do ser humano com o mundo. Sem eles, o número de 
tarefas que uma pessoa realiza durante o dia seria muito inferior ao que costuma executar atualmente.

Um aparelho de som, por exemplo, por mais que existam $n$ modelos diferentes, os controles principais possuem um padrão, um símbolo característico - no caso do botão play, um triângulo - fazendo com que seus usuários o reconheçam e o utilizem sem grandes dificuldades. Porém, se todo o aparelho de som utilizasse uma linguagem diferente, além de gerar uma grande confusão em seus consumidores, estes gastariam uma boa parte de seu tempo para aprender a utilizar o aparelho cada vez que comprassem um modelo mais atual.

De acordo com Garrett (2011), esse tempo gasto para adaptar-se a uma nova linguagem acaba sendo frustrante, pois uma tarefa que seria simples acaba tornando-se lenta e complexa pela retirada de uma convenção da qual o usuário já estava acostumado. Em conformidade, Nielsen e Loranger (2007) afirmam que $80 \%$ ou mais dos sites utilizam abordagens semelhantes de design, uma vez que os usuários já esperam que certos elementos padrões funcionem da forma como estão habituados em suas experiências anteriores de uso.

Fazer a utilização de metáforas que representem a experiência com o mundo real também é uma alternativa eficaz para ajudar os usuários a absorverem mais rápido as funcionalidades do sistema. O uso do ícone da lixeira no desktop do computador, por exemplo, é uma maneira bastante efetiva de simbolizar a exclusão de arquivos indesejados. A única ressalva feita por Garrett (2011) quanto ao uso de metáforas, é a constatação de que não haverá interpretações ambíguas em função dos costumes provenientes de culturas distintas da qual o projeto foi desenvolvido.

Já o design de interface é responsável por organizar todos os elementos da interface, como botões, menus de navegação, áreas de buscas e demais componentes, com o intuito de simplificar a compreensão e utilização dos usuários, auxiliando-os no cumprimento de seus objetivos.

De acordo com Garrett (2001), interfaces de sucesso são aquelas nas quais os usuários não gastam tempo com aspectos irrelevantes para sua experiência conseguindo de imediato identificar os elementos que os ajudarão no cumprimento de suas tarefas.

O design de navegação, por sua vez, tem a função de orientar o usuário, auxiliando-os a se locomover pelas páginas. Segundo Garrett (2011), o projeto de navegação de qualquer site deve atender a três objetivos simultaneamente: disponibilizar links para todas as páginas que compõem o projeto; explicar a ligação que existe entre os links, distinguindo quais são mais importantes e suas diferenças relevantes, facilitando a escolha dos usuários; e comunicar a relação entre o link clicado e a página de destino para a qual o usuário foi direcionado.

Vale ressaltar, como afirma Garrett (2011), a relevância de todas as páginas possuírem uma navegação consistente, informando aos usuários onde eles estiveram, onde estão e onde podem ir. Com a popularização de sistemas de busca como o Google, por exemplo, os usuários podem acessar o site por meio de qualquer página que, na grande maioria das vezes, não é a página principal.

Já o design de informação tem a função de organizar a apresentação do conteúdo de forma atrativa e eficaz sem exigir esforço cognitivo por parte do usuário para compreendê-lo. Os elementos de informação devem refletir exatamente a maneira como os usuários pensam que eles devem estar organizados e agrupa- 
dos, servindo de apoio às suas tarefas dentro do sistema. Para isso, é importante a utilização de padrões e convenções amplamente utilizados na internet, como já citado anteriormente, visto que, segundo Nielsen e Loranger (2007), os padrões aumentam a sensação de domínio dos usuários em relação a um site, ajudando-os a cumprir suas tarefas e deixando-os satisfeitos com o sistema.

Lowdermilk (2013), Garrett (2011), Unger e Chandler (2010) defendem o uso de wireframes para tornar visível, tanto para a equipe de projeto quanto para os usuários, os resultados das pesquisas e análises que estão sendo materializados nessa etapa do projeto.

Os wireframes são protótipos de baixa fidelidade de uma página do site ou aplicativo que geralmente são apresentados em preto e branco ou em tons de cinza, desprovidos de elementos gráficos. Sua função, segundo Unger e Chandler (2010), é a validação dos elementos da página constatando assim se o produto está atendendo as expectativas propostas.

Unger e Chandler (2010) ainda argumentam que todo o processo de construção da experiência deve incluir a prototipagem independente do material utilizado para sua concepção. O protótipo pode ser elaborado a partir de um simples esboço feito à mão, storyboar$d s$, recortes de papelão ou protótipos digitais que possuem um alto grau de fidelidade com o produto final, provendo aos usuários um ambiente mais realista.

Decidido os detalhes específicos de esqueleto da interface, o último plano é intitulado por Garrett (2011) como plano de superfície. Nele são projetados os aspectos por meio dos quais os usuários têm o primeiro contato com o produto, o chamado design sensorial. Segundo o autor, a junção do conteúdo, funcionalidade e estética conclui o projeto que agrada os sentidos e simultaneamente cumpre as metas estipuladas nos quatro planos anteriores.

Toda a experiência com produtos, serviços e também com o mundo, de acordo com Garrett (2011), acontece por meio da visão, audição, tato, olfato e paladar. No processo de construção, a etapa anterior a experimentação do produto pelos usuários é o momento em que o design de experiência escolhe qual dos sentidos irá ser explorado.

No caso do olfato e paladar, com exceção de alimentos, perfumes ou algum outro produto que possui algum tipo de apelo relacionado ao aroma, conforme afirmação de Garrett (2011), raramente são considerados pelos UX Designers.

Em relação ao tato, o campo que mais faz uso desse sentido é o design industrial, principalmente na área de ergonomia que possui como foco de estudo as interações entre os seres humanos e máquinas.

A audição desempenha um papel relevante na experiência de diversos produtos, sendo utilizado não somente para informar o usuário, mas também para atribuir personalidade ao produto.

Já a visão, na grande maioria dos produtos, desempenha um papel fundamental para a experiência do usuário. Segundo Garrett (2011), o design visual não é somente uma questão de estética, de gostar ou não gostar da aparência de um produto, visto que cada indivíduo possui uma opinião pessoal a respeito do que considera um design visualmente agradável. Ao invés de concentrar-se naquilo que seria esteticamente atraente, o autor sugere fazer escolhas estratégicas visando os objetivos estabelecidos nos demais planos.

Da mesma forma, Unger e Chandler (2010), acrescentam que o design visual de um produto afeta não somente a compreensão da mar- 
ca, mas igualmente a confiança depositada no produto. Um design visual eficaz atinge o subconsciente do usuário, fazendo com que ele reconheça o valor e a relevância do produto sem que haja tempo para julgamentos conscientes.

Uma forma simplificada de validar o design visual de um produto, segundo Garrett (2011), é responder as seguintes perguntas: para onde o olho vai primeiro; qual elemento do projeto chama mais a atenção dos usuários; o que o usuário olha primeiro, condiz com os objetivos estratégicos do produto.

Segundo o autor, o movimento dos olhos pela página não acontece de forma aleatória, mas ocorre devido a um conjunto complexo de instintos naturais que todos os seres humanos possuem em resposta a estímulos visuais. Para os designers, essas respostas podem ser manipuladas com o uso de uma variedade de técnicas visuais desenvolvidas ao longo dos séculos, capazes de atrair e direcionar a atenção dos usuários.

Apesar da disponibilidade de vários princípios de design comprovados por meio de pesquisas que se aplicam a maioria dos usuários, Unger e Chandler (2010), defendem a criação de princípios específicos baseados no público-alvo do projeto.

Ainda segundo os autores, o processo de design centrado na experiência do usuário não termina na fase de definição e nem concepção do produto, como acontece em muitas empresas. Unger e Chandler (2010) alertam para a importância de testar o site ou aplicativo com usuários reais antes de seu lançamento para reparar possíveis erros que podem não terem sido detectados nas etapas anteriores.

\section{Considerações Finais}

Este artigo procurou demonstrar que o User Experience Design não é um simples termo ou variação de uma disciplina já existente. Ao contrário, é um campo que possui um sólido embasamento teórico resultante de mais de um século de estudos, conforme afirmação de Buley (2013), e que se faz cada vez mais presente e fundamental para se sobressair em meio a um mercado tão concorrido.

Nas três metodologias descritas foi possível observar a semelhança nas divisões das etapas, com exceção das nomenclaturas e diferentes quantidades de estágios que, no geral, se complementam tendo em vista que a mesma fase do projeto é analisada sob pontos de vista distintos.

Para Under e Chandler (2010) todos os projetos possuem um contexto mais abrangente que deve ser compreendido e integrado ao planejamento. Nomeado como ecossistema do projeto, esse tópico consiste no conhecimento do ambiente organizacional da empresa, do tipo de projeto que será desenvolvido e das pessoas que farão parte da equipe.

Na visão de Lowdermilk (2013), é de grande relevância a definição de uma meta a ser cumprida pela equipe com a finalidade de ser validada ao final do projeto.

Já Garrett (2011) intitula a primeira etapa do projeto como plano de estratégia, no qual são definidos os objetivos do produto e as necessidades dos usuários que servirão como suporte para as demais etapas. Em consonância, Lowdermilk (2013) defende a importância de um plano estratégico para melhor compreensão das expectativas dos usuários evitando desse modo a perda de tempo e dinheiro projetando algo desnecessário e sem utilidade para seus consumidores. 
Definido os objetivos do projeto, a próxima fase é a coleta de requisitos dos usuários. Para isso, são realizadas pesquisas para definir grupos primários que, a partir dos dados coletados, serão utilizados para a criação de personas.

Tanto Garrett (2011) quanto Lowdermilk (2013) e Unger e Chandler (2010) defendem a criação de personas, que consiste em documentos que descrevem personagens fictícios baseados em usuários reais, uma vez que eles servem como constantes lembretes dos usuários para validação de ideias e resoluções de conflitos durante o processo de desenvolvimento do projeto.

Finalizada a parte de estratégia, a próxima etapa, de acordo com Garrett (2011), Lowdermilk (2013) e Unger e Chandler (2010) é a fase em que as necessidades dos usuários e os objetivos do produto são transformados em requisitos dos usuários e requisitos funcionais do sistema que, no modelo de Garrett (2011), é designado como plano de escopo.

Nessa etapa, Unger e Chandler (2010) e Garrett (2011) alertam para o surgimento de novas ideias que devem ser transformadas em requisitos para que não haja o desperdício de nenhuma sugestão. Segundo os autores são essas ideias que fornecem insights para o projeto, desde que alinhadas com os objetivos estratégicos anteriormente esboçados.

O próximo estágio, denominada por Garrett (2011) como plano de estrutura, consiste no desenvolvimento de uma estrutura conceitual no qual as questões abstratas da estratégia e do escopo começam a se tornar fatores concretos para a experiência do usuário. As ferramentas utilizadas nessa fase são a arquitetura de informação e o design de interação.
Na etapa seguinte, definida por Garrett (2011) como plano do esqueleto, é o aperfeiçoamento da estrutura criada no plano anterior, focando em aspectos específicos da interface por meio do design de interface, design de navegação e design de informação.

Garrett (2011) destaca a importância da utilização de metáforas que representem a experiência das pessoas com o mundo real e convenções que já são amplamente utilizadas visando à melhor interação do usuário com a interface.

Lowdermilk (2013), Garrett (2011), Unger e Chandler (2010) defendem o uso de wireframes para tornar visível, tanto para a equipe de projeto quanto para os usuários, os resultados das pesquisas e análises que estão sendo materializados nessa fase.

Concluída a etapa anterior, a última etapa, nomeada por Garrett (2011) como plano de superfície, o foco é nos aspectos por meio dos quais os usuários têm o primeiro contato com o produto, o chamado design sensorial. De acordo com o autor, a junção do conteúdo, funcionalidade e estética conclui o projeto que agrada os sentidos ao passo que cumpre as metas estipuladas nas etapas anteriores.

Finalizando as considerações aqui apontadas, ainda segundo os autores, o processo de design centrado na experiência do usuário, não termina efetivamente na fase de definição e nem concepção do produto, como acontece na maioria das empresas. Unger e Chandler (2010) alertam para a importância de testar o site ou aplicativo com usuários reais antes de seu lançamento para reparar possíveis erros que podem não terem sido detectados nas etapas anteriores. 


\section{Referências}

BULEY, Leah. The User Experience Team of One: A Research and Design Survival Guide. New York: Rosenfeld Media, 2013.

GARRETT, James J. The Elements of User Experience: User-Centered Design for the Web and Beyond. Berkeley: New Riders, 2011.

LOWDERMILK, Travis. Design Centrado no Usuário: um guia para o desenvolvimento de aplicativos amigáveis. São Paulo: Novatec, 2013.

MORVILLE, Peter. The Definition of Information Architecture. Ann Arbor: Semantic Studios, 2002. Disponível em: <http://semanticstudios.com/the_definition_of_information_architecture/> Acesso em: 24 out. 2014.

MORVILLE, Peter. User Experience Design. Ann Arbor: Semantic Studios, 2004. Disponível em: <http://semanticstudios.com/user_experience_design/> Acesso em: 27 out. 2014.

NIELSEN, Jakob; LORANGER, Hoa. Usabilidade na Web: projetando Websites com qualidade. Trad. Edson Furmankiewicz e Carlos Schafranski. Rio de Janeiro: Elsevier, 2007.

NIELSEN, Jakob; NORMAN, Don. The Definition of User Experience. In: NIELSEN NORMAN GROUP. Evidence-Based User Experience Research, Training, and Consulting. [site]. Fremont, CA, [2014?]. Disponível em: <http://www.nngroup.com/articles/definition-user-experience/> Acesso em: 25 set. 2014.

NORMAN, Don. Human Error? No, Bad Design. In: DON Norman: designing for people. [site]. [S.I.]: jnd.org., [2014]. Disponível em: <http://www.jnd.org/dn.mss/human_error_no_bad.html> Acesso em: 16 set. 2014.

SAFFER, Dan. Designing for Interaction: Creating Smart Applications and Clever Devices. Berkeley: New Riders, 2007.

UNGeR, Russ; CHANDleR, Carolyn. Guia Para Projetar UX. Rio de Janeiro: Alta Books, 2010.

VIANNA, Maurício et al. Design Thinking: inovação em negócios. Rio de Janeiro: MJV Press, 2012. 
Submetido para avaliação em 15 de abril de 2015.

Aprovado para publicação em 28 de outubro de 2015.

Milene Rocha de Sousa - Faculdades Metropolitanas Unidas, São Paulo, BR. E-mail: milene.rs@gmail.com. João Vicente Cegato Bertomeu - Universidade Federal de São Paulo, São Paulo, BR. E-mail: jvcbertomeu@unifesp. br. 